\title{
A dual level model for speciation by multiple pericentric inversions
}

\author{
MAX KING \\ Museum of Arts and Sciences, GPO Box 4646, Darwin N. T. 0801, Australia
}

\begin{abstract}
A considerable body of evidence suggests that the deleterious meiotic effects of pericentric inversions in $F_{1}$ hybrids can be overcome by changes in chiasma location and various means of nonhomologous pairing. Such overriding mechanisms may render pericentric inversions benign and increase the likelihood of their fixation in population isolates. It has been argued that overriding mechanisms of this type negate the involvement of pericentric inversions as reproductive isolating mechanisms in speciation. It is suggested, however, that the involvement of pericentric inversions in speciation should be considered on two levels. First, that by reducing meiotic effects in $F_{1}$ hybrids, overriding mechanisms facilitate the fixation of pericentric inversions. Secondly, when contact hybridization occurs between the chromosomally derived and parental populations second-level effects may be encountered. That is, the recombinational effects of pericentric inversion differences on coadapted gene complexes (sensu Brncic, 1954; Shaw \& Coates, 1983) enforce profound inviability barriers in $\mathrm{F}_{2}$ and backcross matings. In this way, multiple pericentric inversions may act as significant post-mating isolating mechanisms, whereas individual inversions with less significant second-level effects may not.
\end{abstract}

Keywords: chromosomes, inviability, pericentric inversions, speciation.

\section{The model}

The action of chromosomal rearrangements as postmating isolating mechanisms in those situations when a parental and chromosomally derived population contact and hybridize, is based on the expectation that the hybrid will have reduced fertility because of the meiotic problems that chromosomal heterozygosity generates. Consequently, the difficulty of establishing a population which has a derived negatively heterotic arrangement is a fundamental problem of chromosomal speciation theory.

The status of pericentric inversions as potential post-mating isolating mechanisms has been queried on a number of occasions, because of certain anomalies encountered in inversion heterozygotes, which override any deleterious meiotic effects (John \& King 1977, 1980; John 1981; King 1984, 1987). Four separate mechanisms have been implicated in this process. First, chiasma location may be changed to a terminal position, or these may occur outside the inversion loop (Hale, 1986). Secondly, non-homologous pairing of the inverted segment in heterozygotes may occur in pachytene. This has been observed by meiotic analysis in numerous Orthopteran species (Nur, 1968;
Schroder, 1968; John \& King, 1977, 1980) while the analysis of synaptonemal complexes has confirmed this process in grasshoppers (Fletcher \& Hewitt, 1978) and in rodents (Davisson et al., 1981; Greenbaum \& Reed, 1984; Hale, 1986). Thirdly, Moses et al. (1984) and Tease \& Fisher (1988) have described reverse chromosome pairing in inversion heterozygotes, i.e. association of telomeric and centromeric ends followed by synapsis. Fourthly, Moses (1977) detailed the process of synaptic adjustment, whereby an inversion loop is formed in the synaptonemal complex of heterozygotes in early pachytene, but as pachytene progresses the loops become smaller until none remain, i.e. nonhomologous resynapsis occurs.

It should be pointed out that in certain situations several of the synaptic mechanisms may be found in the one heterozygote along with inversion loops (Stack \& Anderson, 1988). In other cases such mechanisms are absent and synaptonemal complexes form inversion loops (Moses et al., 1982; Poorman et al., 1981; Stack \& Anderson, 1988). If overriding mechanisms of the types described above are present, there is little doubt that pericentric inversions could reach fixation in isolated populations by stochastic processes alone (sensu Lande, 1984). Equally, they could remain as neutral 
and balanced polymorphisms. Without such mechanisms inversions would be faced with the same difficulties of fixation that other deleterious mutations have.

We can no longer argue with confidence, however, that those apparently neutral pericentric inversions, which can reach fixation because of their meiotic overriding mechanisms, cannot play a role in speciation as post-mating isolating mechanisms, because it appears likely that other factors are involved. Dobzhansky (1951) demonstrated that inversion heterozygotes which carry chromosomes derived from a single population, usually exhibit heterosis. If the chromosomes were derived from different populations, however, heterosis did not necessarily result. This discrepancy was attributed to the disruption of coadapted gene complexes which had been established for each of the parental populations, in the structural hybrid.

These results were extended by Vetukhiv (1953) and Brncic (1954), who introduced cytologically indistinguishable chromosomes with a uniform gene arrangement into populations of Drosophila pseudoobscura, which had different genetic backgrounds. In both studies, $F_{1}$ hybrids showed heterosis, whereas $F_{2}$ and $F_{3}$ hybrids were less viable than both the $F_{1}$ and parental strains. The reduction in viability was attributed to the effects of recombination between the chromosomes derived from different populations, disintegrating the coadapted gene complexes.

Shaw \& Coates (1983) and Shaw et al., (1986) also detected a similar second level of effect in hybrids between genomes distinguished by multiple fixedpericentric inversions. The grasshopper Caledia captiva had four cytologically recognizable chromosome races. The Moreton and Torresian races differ by pericentric inversions in 8 of the 12 members of the complement and also have numerous $\mathrm{C}$-band differences established between them. Experimental hybridization between these cytotypes produced viable and fertile $F_{1}$ hybrids, whereas some $F_{2}$ hybrids were totally inviable and backcrosses were from 53 to 64 per cent inviable. A major contribution of this inviability was correlated with the redistribution of chiasmata in $F_{1}$ hybrids. Because the Moreton cytotype has a distinct cline in chromosome morphology between northern and southern populations, the latter of which are indistinguishable from the Torresian cytotype, Shaw et al., (1986) were able to construct a series of crosses between cytologically identical and different, and electrophoetically identical and different populations. These authors were able to partition the contribution made to inviability by the chromosomal and genic differences. Thus, 54 per cent of the inviability was attributed to genic and 42 per cent to chromosomal differences. Most significanly, the impact of the inver- sion differences was related to second level recombinational effects rather than first level effects (Shaw et al., 1986).

The implications of these findings on the possibility of pericentric inversions acting as post-mating isolating mechanisms are significant in four respects. First, in a derived population distinguished by multiple pericentric inversions, the question of how such changes could ever reach fixation when they provide second-level inviability barriers in later crosses (i.e. $F_{2}$ and backcross), arises. The most reasonable answer is that the individual inversions must have been established sequentially, so that their effects on the fitness of the population were minimized. That is, it is assumed that the second-level effects on viability are less profound with single inversions. If the inversions were established simultaneously rather than sequentially, it is probable that the second-level effects would achieve the same level of inviability encountered in $F_{2}$ and backcross and consequently none could reach fixation. Nevertheless, the possibility of multiple inversions simultaneously reaching fixation in populations undergoing particular dynamic changes cannot be ruled out (Rouhani \& Barton, 1987).

Secondly, it is probable that the second-level recombination effects described by Shaw et al. (1986) in their hybridization studies, are a product of the disruption of numerous pericentric inversions acting in concert. Presumably, genomes with one or a few pericentric inversions established would provide less profound second-level fitness effects in hybrids Thirdy, the fact that pericentric inversions appear to have no impact on fertility in $F_{1}$ hybrids and profound effects in later crosses, suggests that those studies which have discounted chromosomal effects on the basis of $F_{1}$ results alone are suspect. The implication is that an analogous second-level effect may apply to other types of arrangement. Fourthly, this dual level situation provides a new perspective on the role played by pericentric inversions as post-mating isolating mechanisms in speciation. The following general model is immediately apparent.

1 If level one overriding mechanisms are present, pericentric inversions established in an isolated population are not selected against because of their heterozygosity and can thus reach fixation due to stochastic processes (sensu Lande, 1984).

2 Pericentric inversions established in a concerted fashion reach fixation sequentially in the daughter population. Presumably, the second-level fitness effects are individually small when one or two changes are established at a time.

3 When contact is again made between the parental and daughter populations, which are now distinguished by numerous fixed inversion differences, viable $F_{1}$ 
hybrids can form in the contact zone due to the overriding of first level mechanisms.

4 Further inbreeding and backcrossing lead to profound sterility barriers due to the second level effects; resulting in a narrow hybrid zone with an absence of gene flow across it. The magnitude of second-level effects will be proportional to the number of fixed inversion differences established between parental and daughter populations.

Thus, the overriding of first level effects facilitates the fixation of neutral pericentric inversions, whereas second level effects allow these to operate as major post-mating isolating mechanisms. That is, the overriding mechanisms which render pericentric inversion heterozygotes as benign in $F_{1}$ hybrids contribute to the increased likelihood of the inversions eventual fixation. It is only when secondary contact is made between populations with multiple inversion fixed that hybrids formed in the contact zone can display the profound second-level inviability effects.

Two basic assumptions are necessary for this model to be general. First, that the second-level inviability effects described by Vetukhiv (1953) and Brncic (1954) in Drosophila pseudoobscura and by Shaw \& Coates (1983) in Caledia captiva are the same; are also present in other organisms; and are a product of pericentric inversion heterozygosity. Secondly, that the secondlevel effects of individual inversions are less deleterious than those associated with multiple inversions and that they may be additive. Clearly, this model for chromosomal speciation is not universal since the existence of balanced polymorphisms involving multiple pericentric inversions (see John \& King 1977, 1980 for examples) suggest that some inversions lack second-level effects. Nevertheless, those species in which second-level inversion effects are present have a profound postmating isolating mechanism which could be implicated in chromosomal speciation.

\section{Acknowledgements}

Many thanks to Dr Les Christidis for his comments on the manuscript.

\section{References}

BRNCIC, D. 1954. Heterosis and the integration of the genotype in geographic populations of Drosophila pseudoobscura. Genetica, 39, 77-88.

DAVISSON, M. T., POORMAN, P. A., RODERICK, R. H. AND MOSES, M. J. 1981. A pericentric inversion in the mouse. Cytogenet. Cell Genet. 30, 70-76.

DOBZHANSKY, т. 1951. Genetics and the Origin of Species, 3rd edn. Columbia University Press, New York.
FLETCHER, H. L. AND HEWITT, G. M. 1978. Non-homologous synaptonemal complex formation in a heteromorphic bivalent in Keyacris scurra (Morabinae, Orthoptera). Chromosoma (Berl.) 65, 271-281.

GREENBAUM, I. F. AND REED, M. J. 1984. Evidence for heterosynaptic pairing of the inverted segment in pericentric inversion heterozygotes of deer mice (Peromyscus maniculatus). Cytogenet. Cell Genet., 38 106-111.

HALE, w. W. 1986. Heterosynapsis and suppression of chiasmata within heterozygous pericentric inversions of the sitka deer mouse. Chromosoma (Berl.), 94, 425-432.

JOHN, B. 1981. Chromosome change and evolutionary change: a critique. In: Atchley, W. R. and Woodruff, D. (eds) Evolution and Speciation. Essays in honour of M. J.D. White, Cambridge University Press, Cambridge, pp. 23-51.

JOHN, B. AND KING, M. 1977. Heterochromatin variation in Cryptobothrus chrysophorus. 1. Chromosome differentiation in natural populations. Chromosoma (Berl.), 64, 219-239.

JOHN, B. AND KING, M. 1980. Heterochromatin variation in Cryptobothrus chrysophorus. III. Synthetic hybrids. Chromosoma (Berl.) 78, 165-186.

KING, M. 1984. Karyotypic evolution in Gehyra (Gekkonidae, Reptilia). IV. Chromosome change and speciation. Genetica, 64, 101-114.

KING, M. 1987. Chromosomal rearrangements, speciation and the theoretical approach. Heredity, 59, 1-6.

LANDE, R. 1984. The expected fixation rate of chromosomal inversions. Evolution, 38, 743-752.

MOSES, M. J. 1977. Microspreading and the synaptonemal complex in cytogenetic studies. Chromosomes Today, 8 , 90-103.

MOSES, M. J., DRESSER, M. E. AND POORMAN, P. A. 1984. Composition and role of the synaptonemal complex. Symp. Soc. Exp. Biol., 38, 245-270.

MOSES, M. J., POORMAN, P. A., RODERICK, T. H. AND DAVISSON, M. T. 1982. Synaptonemal complex analysis of mouse chromosomal rearrangements. IV. Synapsis and synaptic adjustment in two paracentric inversions. Chromosoma (Berl.), 84, 457-474.

NUR, U. 1968. Synapsis and crossing-over within a paracentric inversion in the grasshopper Camnula pellucida. Chromosoma (Berl.), 25, 198-214.

POORMAN, P. A., MOSES, M. J., DAVISSON, M. T. AND RODERICK, T. H. 1981. Synaptonemal complex analysis of mouse chromosomal rearrangements. III. Cytogenetic observations on two paracentric inversions. Chromosoma (Berl.), 83, 419-429.

ROUHANI, S. AND BARTON, N. H. 1987. The probability of peak shifts in founder populations. J. Theor. Biol., 126, 51-62.

NUR, U. 1968. Synapsis and crossing-over within a paracentric inversion in the grasshopper Camnula pellucida. Chromosoma (Berl.), 25, 198-214.

POORMAN, P. A., MOSES, M. J., DAVISSON, M. T. AND RODERICK, T. H. 1981. Synaptonemal complex analysis of mouse chromosomal rearrangements. III. Cytogenetic observations on two paracentric inversions. Chromosoma (Berl.), 83, 419-429. 
ROUHANI, S. AND BARTON, N. H. 1987. The probability of peak shifts in founder populations. J. Theor. Biol., 126, 51-62.

SCHROEDER, G. L. 1968. Pericentric inversion polymorphism in Trimerotropis helferi (Orthoptera:Acrididae) and its effects on chiasma frequency. $\mathrm{PhD}$ thesis University of California at Davis.

SHAW, D. D. AND COATES, D. J. 1983. Chromosomal variation and the concept of the coadapted genome - a direct cytological assessment. In: Bennett, M. and Brandham, P. (eds) Kew Chromosome Conference II. George Allen and Unwin, London, pp. 207-216.

SHAW, D. D., COATES, D. J. AND WILKINSON, P. 1986. Estimating the genic and chromosomal components of reproductive iso- lation within and between subspecies of the grasshopper Caledia captiva. Can. J. Genet. Cytol., 28, 686-695.

STACK, S. AND ANDERSON, L. 1988. An analysis of synaptic adjustment, length and twisting of synaptonemal complexes in maize. In: Brandham, P. E. (ed.) Kew Chromosome Conference III. HMSO, London, pp. 299-312.

TEASE, C. AND FISHER, G. 1988. Chromosome pairing in foetal oocytes of mouse inversion heterozygotes. In Brandham, P. E. (ed.) Kew Chromosome Conference III. HMSO, London, pp. 293-298.

VETUKHIV, M. 1953. Viability of hybrids between local populations of Drosophila pseudoobscura. Proc. Nat. Acad. Sci., U.S.A., 39, 30-34. 